\title{
A ECONOMIA E O DIREITO DE PROPRIEDADE: DIÁLOGOS FEA \& LARGO SÃO FRANCISCO
}

\author{
Decio Zylbersztajn \\ Professor de Economia da Faculdade de Economia e \\ Administração da Universidade de São Paulo \\ Rachel Sztajn \\ Professora Associada do Departamento de Direito \\ Comercial da Faculdade de Direito da \\ Universidade de São Paulo
}

Resumo:

O presente texto foi concebido no segundo encontro do Centro de Estudos de Organizações e Instituições da Universidade de São Paulo, cujo objetivo é pautar as discussões entre o Direito e Economia, com vistas ao avanço institucional no Brasil.

Abstract:

The present text was conceived in the second meeting of the Organizations and Institutes of São Paulo's University Study's Center, which aim is methodize the discussions between Law and Economy, in order to the institucional advance in Brazil.

Unitermos: Economia; direito de propriedade.

1. A Economia e o Direito de Propriedade.

A análise econômica do direito de propriedade representa a linha de sustentação fundamental dos estudos das diferentes vertentes que estudam a Economia do Direito, entre as quais Mercuro e Medema (1997) citam a Escola de Chicago, a Teoria da Escolha Pública, a Escola Institucionalista e a Nova Economia Institucional, esta última sendo uma área do conhecimento que releva a importância das instituições como promotoras do desenvolvimento econômico e as considera passíveis de análise.

No Direito se diz que o direito de propriedade é tido como um feixe que engloba os direitos de uso, usufruto e abuso, e que confere o exercício da exclusão sobre a coisa, que permite afastar terceiros que dela pretendam se apropriar, usar ou gozar. Em Economia, os trabalhos seminais de Ronald Coase, de modo especial The Nature of the Firm (1937) e The Problem of Social Cost (1954), abordaram de forma inovadora o tema da propriedade, levando o que Stigler posteriormente denominou como "Teorema de Coase" 
Partindo do conceito de que o que se negocia não são os bens objeto de direito, mas sim direitos de propriedade sobre dimensões de bens, Coase propõe que, na ausência de "custos de transação" a alocação ou distribuição inicial dos direitos de propriedade sobre as dimensões dos bens não terá importância, pois os agentes negociarão a transferência dos bens a custo zero, podendo realocar de modo eficiente tais direitos. Assim construiu-se boa parte da Economia do Direito e da Nova Economia Institucional, que está voltada primordialmente para a lógica econômica dos arranjos contratuais relacionados à criação dos direitos.

A proposta de Coase, talvez melhor explicitada no seu discurso ao receber o Prêmio Nobel em 1972, pode ser desdobrada da seguinte forma:

"O mundo real apresenta friç̧ões que denominamos "custos de transação", fricções estas causadas por assimetrias de informação que dificultam ou impedem que os direitos de propriedade sejam negociados a custo zero."

Os "custos de transação" são afetados pelo sistema legal e por normas não-positivadas, que recaem sobre a alocação dos direitos de propriedade.

Outros autores, partindo dos estudos de Coase ampliaram o trabalho, tendo como foco a importância das instituições para o desenvolvimento sócioeconômico do impacto no controle dos "custos de transação" e, portanto, na alocação do direito de propriedade. Esta foi a dimensão explorada por Douglas North (1990) na área macroinstitucional.

Outra vertente importante é a que considera os impactos da alocação do direito de propriedade sobre a eficiência e desempenho das organizações. Esta vertente, que podemos chamar de microinstitucional, parte da importância do direito de propriedade para o estudo das organizações e vem sendo desenvolvida por Oliver Williamson (1985).

Este texto considera apenas algumas dimensões introdutórias do estudo da economia do direito de propriedade, limitando-se a levantar conceitos básicos mais do que a aprofundá-los. Assim, trata do conceito de direito de propriedade, a economia dos direitos exclusivos, o efeito das formas de propriedade sobre os resultados econômicos e o surgimento e importância do direito de propriedade. O texto baseia-se, fortemente, no trabalho de T. Eggertsson (1990) e de Yoram Barzel (1997).

Conceito de Direito de Propriedade em Economia.

Há na literatura econômica várias categorias de direitos de propriedade. Ricketts (1987) define as categorias de direitos privados, direitos comunais e direitos coletivos e Eggertsson (1990) inclui o Direito do Estado.

Para o Direito os bens se classificam em:

Bens móveis ou imóveis, divisíveis ou indivisíveis, singulares ou coletivos, públicos e particulares, corpóreos e incorpóreos, fungíveis ou infungiveis, 
disponiveis e indisponíveis e coisas fora do comércio (art. 43 e ss do Código Civil). Demais disso, bens podem ser consumíveis ou-não.

Considere-se os direitos de uso e de transferência dos recursos, sendo que o primeiro pode ou-não abranger o direito à destruição do recurso. A possibilidade de transferir os direitos de propriedade afeta, diretamente, seu valor econômico. Entretanto tal valor será afetado também pela existência de sistemas de garantia (coerção - enforcement) quanto ao exercício dos direitos.

A garantia de exercício dos direitos pode ser oferecida pelo Estado ou, em certos casos, de forma privada, quando normas sociais não-positivadas atuam muitas vezes como mecanismo redutor de "custos de transação", advindo daí a lógica da sua emergência. Quando a coerção privada, que decorre das normas informais, coincide com os incentivos providos pelo sistema legal, o custo de coerção é baixo; quando não, elevados custos de coerção podem emergir na sociedade. Inexistindo essa definição dos direitos, seja por normas sociais seja pelo Estado, as pessoas tenderão a defini-los em benefício próprio ou de seu grupo.

Dado que os direitos de propriedade são muitas vezes compartilhados, a possibilidade da sua realocação e transferência dependerá da existência de "custos de transação" O já citado paradigma básico de Coase é o pressuposto da irrelevância da alocação inicial dos direitos de propriedade na ausência de "custos transacionais" A dificuldade real é que eles existem.

A realocação dos direitos de propriedade é regulada por contratos que definem os termos da troca tanto nas condições do uso do recurso como na divisão dos resultados. Sua eficiência depende da existência de mecanismos institucionais legais, que garantam o cumprimento das promessas sempre que a contratação e a execução da operação forem defasadas no tempo, como no caso dos contratos de execução diferida, por exemplo.

Tanto os contratos baseados em disciplina positiva, como os acordos informais, suportados em outros mecanismos, surgem a partir da necessidade de dar eficácia a uma relação de troca de direitos de propriedade em ambiente no qual os agentes podem tomar decisões oportunísticas, em que as informações podem ser assimétricas e em que a racionalidade limitada impede a redação de contratos completos no sentido que à palavra cabe na literatura de Economia e Direito.

Para a nova economia das instituições as "firmas" (organizações) são consideradas como um "nexo" de contratos, sendo que na firma clássica de um empresário controlador ele representa o agente que estrutura o conjunto de contratos, bilaterais, entre individuos e entre "firmas"

Surgimento dos Direitos de Propriedade.

O conceito básico de que as instituições emergem de modo a proteger direitos de propriedade, afetando os "custos de transação", leva a indagar por que existem instituições não-ótimas. Segundo Eggerttson (1990) ainda que a definição e garantias de direitos de propriedade estejam associadas ao desenvolvimento econômico, 
em um mundo de "custos de transação" positivos, toda a sorte de interferências políticas na alocação dos direitos de propriedade acaba por afetar a sua definição.

Alguns modelos explicativos do surgimento dos direitos de propriedade coexistem na literatura. O primeiro é o modelo desenvolvido por Demsetz (1967), que se desenvolve a partir de bases quase antropológicas e se abstém de modelar as instituições políticas. No seu artigo seminal denominado "Towards a Theory of Property Rights", Demsetz apresenta um modelo que analisa a ação dos índios em duas regiões no Canadá, apresentando um problema típico do que a literatura veio denominar como " tragédia dos comuns" Em um caso a caça, o autor revela o problema da exaustão, com o desaparecimento das espécies na primeira região, enquanto que na segunda isto não ocorre. $\mathrm{O}$ autor relaciona os dois fatos com a natureza fisica das duas regiões, uma de floresta fechada e outra de planície. Emergem duas diferentes estruturas que disciplinam o direito de propriedade sobre a terra nas áreas. Onde, por razões naturais, não existe problema de desaparecimento das espécies (exaustão), predomina a propriedade comum e onde o problema ocorre, emerge o direito de propriedade privado como forma de controlar o uso dos recursos.

Ou seja, existe incentivo econômico para as diferentes sociedades investirem recursos para definir e preservar os direitos de propriedade. Eggertsson (1990) chama o modelo de "ingênuo" no sentido de que ignora o processo político, mas que tem utilidade para o estudo histórico do desenvolvimento das instituições.

Uma variante do modelo considera os custos de exclusão e os custos de governança interna do sistema de oferta de direitos de propriedade, tendo sido utilizado por Alston, Libecap e Mueller (1999) em estudo sobre a formação de direitos de propriedade da terra na região da Amazônia.

Modelos alternativos estudam situações nas quais os direitos de propriedade não emergem, seja devido aos custos politicos ou por razões de intervenção pública com base em critérios de eqüidade, ou ainda devido a custos de exclusão proibitivos. Aponta-se o caso do sistema comunista que não reconhece direito de propriedade que pertencem à coletividade (Estado) e são insuscetíveis de apropriação pelos particulares.

O terceiro modelo importante baseia-se na ação dos grupos de interesse da sociedade que procuram interferir no processo normativo. Variáveis importantes são os "custos de transação", a possibilidade do efeito carona (free-riding) e a existência de informação assimétrica.

O modelo considera ser dada a estrutura institucional e que os agentes formarão grupos de interesse que otimizarão os seus interesses particulares e comuns. Este modelo se aproxima do modelo de rent-seeking apresentado por Krueger (1974) e Buchanan (1980).

Importante série de estudos com base no modelo de oferta e demanda de direitos de propriedade no Brasil foi desenvolvida por Bernardo Mueller, Gary Libecap e Lee Alston, podendo servir de exemplo para o enfoque que utiliza elementos quantitativos para testar o que utiliza o exemplo da titulação de terras no Norte do Brasil. 


\section{Propriedade das "Firmas".}

Esta vertente estuda os efeitos das formas de propriedade das "firmas" sobre os resultados econômicos.

Importante na origem dos estudos de governança corporativa, os modelos partem do pressuposto de que os resultados das empresas dependerão tanto da estrutura externa de direitos de propriedade (empresas estatais, empresas cooperativas, empresas abertas, sociedades limitadas), quanto, também, da estrutura de direitos de propriedade interna à organização caracterizada pelas regras internas e pela estrutura organizacional.

Toda a literatura gerada a partir do estudo das relações contratuais de propriedade das "firmas" na forma de responsabilidade limitada, conflitos de agência, e regulação do mercado acionário cabem nesta vertente, que redunda na análise da governança corporativa.

Ampla literatura, derivada da tese de Berle e Means (1932), com base nos elevados custos de monitoramento dos agentes no caso de propriedade dispersa das ações, leva à formulação da hipótese do surgimento de mecanismos alternativos para o controle da agência; no caso o risco de take over; ou seja, a competição no mercado de capitais restringe o oportunismo dos agentes e controla problemas de agência, como preferem Jensen e Mekling (1976).

Os estudos das formas de propriedade como as corporações abertas, sociedades limitadas, fundos mútuos, cooperativas e organizações sem fins lucrativos consideram o papel dos incentivos associados aos direitos de propriedade sobre os resíduos e pela responsabilidade existente sobre as iniciativas estratégicas dos que tomam decisões. O problema aqui apresentado se refere ao fato de que, nem sempre, a totalidade dos efeitos das decisões é sentida pelos que decidem, gerando potencial distorção na alocação dos recursos. Fama e Jensen (1985) consideram que na ausência de mercados por direitos residuais existe uma tendência de subinvestimento.

Finalmente um conjunto de contribuições contrasta as empresas estatais em contraposição às de propriedade privada, em especial no recente período caracterizado pelo processo de retirada do Estado da produção, seja com a pura privatização, seja com a criação de mecanismos mistos de contratos de concessão de serviços públicos.

Esse o pano de fundo em que se pretende iniciar a discussão sobre as mudanças legais e institucionais relacionadas à propriedade dos bens de produção, à apropriação dos resultados e a projeção delas sobre o desenvolvimento econômico e reflexos no aperfeiçoamento do bem-estar geral, ou seja, de que forma é possível, partindo do Direito Positivo, melhor a distribuição de renda e aumentar o grau de satisfação da sociedade. 
Bibliografia.

Berle, A and Means, G. The Modern Corporation and Private Property. New York, MacMillan, 1932.

Buchanan, J; Tollinson, R.; Tullok, G. Toward a Theory of the Rent-Seeking Society. College Station:Texas A\&M University Press.1980.

Coase, R. The Nature of the Firm. 1937. In The Firm the Market and the Law.(1988). The University of Chicago Press. Chicago.217p.

Coase, R. The Problem of Social Cost (1954). In The Firm the Market and the Law.(1988). The University of Chicago Press. Chicago. 217p.

Fama, E. F., and Jensen, M. C. "Separation of Ownership and Control. Journal of Law and Economics. 26th June, 1983: 301-25.

Jensen, M. C., and Meckling, W. H. Theory of the Firm: Managerial Behavior, Agency Costs and Ownership Structure. Journal of Financial Economics. 3 - October 1976:305-60.

Krueger, A. O. 1974. The Political Economy of the Rent Seeking Society. American Economic Review 64 (3rd June):291-303.1974.

North, D. C. 1990. Institutions, Institutional Change and Economic Performance. Cambridge University Press.

Williamson, O. E. 1985. The Economic Institutions of Capitalism. The Free Press.

Eggertsson, T. 1990. Economic behavior and institutions. Cambridge surveys of economic literature. Press.

Barzel, Y. 1997. Economic Analysis of Property Rights. Cambridge University

Demsetz, H. 1967. Towards a theory of property rights. American Economic Review 57, n. 2:347-359.

Ricketts, M. 1987. The Economics of Business Enterprise: New Approaches to the Firm. The Harvester Press. 